\title{
LEALTAD Y FIDELIDAD: LA PROCLAMACIÓN DEL REY FernANdo VII EN CARTAgo, PROVINCIA DE Costa RicA, 1809'
}

\section{Guillermo Brenes Tencio}

Grupo de Estudios sobre Arte Público

Latinoamericano (GEAP), Costa Rica

gmobrs@hotmail.com

\section{ESUMEN}

Durante el período colonial, las fiestas reales convierten a las ciudades hispanoamericanas en el escenario público en que se representa el fascinante espectáculo del imaginario monárquico. Todas las colonias del Imperio español en América proclamaban a un monarca físicamente ausente, pero materializado simbólicamente a través de representaciones discursivas e iconográficas. En este escrito se describen y analizan los aspectos más interesantes de la proclamación o ceremonia de jura del rey Fernando VII, en la ciudad colonial de Cartago, entre los días 15 y 23 de enero de 1809.

Palabras clave: ceremonias, ritual de jura, Fernando VII, Napoleón Bonaparte, Cartago colonial, plaza mayor, Costa Rica, historia cultural, siglo XIX.

\section{Abstract}

During the colonial period, the royal celebrations made the Hispanic American cities the public scenario to represent the fascinating spectacle of the imaginary monarch. All the colonies of the Spanish Empire proclaimed a monarch who was physically absent but was symbolically materialized through discursive representations and iconographies. This article describes and analyzes the most interesting aspects of the proclamation or pledge ceremony of the King Ferdinand VII, which took place in the city of Cartago, between January 15th and January 23rd, 1809.

Key words: ceremonies, pledge ritual, Ferdinand VII, Napoleon Bonaparte, colonial Cartago, main square, Costa Rica, cultural history, 19th century.

1 Agradezco profundamente a la Dra. Beatriz Rojas Nieto (Instituto de Investigaciones Dr. José María Luis Mora, México), al Dr. Marco Antonio Landavazo, a la Mtra. Juana Martínez Villa (Universidad Michoacana de San Nicolás de Hidalgo, México) y al Dr. Jaime Valenzuela Márquez (Pontificia Universidad Católica de Chile), por su generoso apoyo bibliográfico y 


\section{Introducción}

La ceremonia de jura fue la celebración regia más importante del Antiguo Régimen, pues, mediante la proclamación, permitía la materialización y el acatamiento de un monarca, incluso aunque estuviera físicamente ausente. El acto de "jurar" era manifestar fidelidad, lealtad y vasallaje al rey, mediante las ceremonias al uso; sin embargo, esta demostración debía ser pública. En efecto, no servía proclamar fidelidad si el acto no era público; así que la obligación de que se diera frente al conjunto de individuos ayudaba a la concienciación de los vasallos del rey (Gayol).

En América, la ceremonia de jura se impuso en el Virreinato del Perú y en el de la Nueva España desde el siglo XVI. Se celebraba en las plazas mayores de todas las localidades y, sobre todo, las ciudades, que veían alterar agradablemente el diario trajín. Innegablemente, dicha ceremonia adquiría un significado especial en los reinos y provincias del Imperio español. ¿Por qué? A diferencia de la metrópoli ibérica, los súbditos de ultramar nunca tuvieron ocasión de conocer directamente a los reyes ni a los príncipes herederos, por lo que su proclamación devenía en la América española en una suerte de presentación virtual del "pacto" entre los vasallos y el rey, en la sociedad colonial (Osorio 7).

Como parte de este acto, realizado con la participación de todo el conjunto social, se lanzaban cientos de monedas y medallas conmemorativas a la jura y proclamación, las cuales mostraban en una de sus caras la efigie del rey para darlo a conocer. En un sentido semejante, la ausencia física del soberano durante la época colonial se subsanaba mediante la utilización de su imagen pintada en los rituales públicos, un dispositivo que

valiosos comentarios a versiones preliminares de este trabajo. Extensivo a la Licda. Eva María Guevara Salazar y al Dr. Franco Fernández Esquivel, colegas y amigos. No obstante, los errores de forma y contenido son únicamente responsabilidad mía. Reconozco al personal del Archivo Nacional de Costa Rica (ANCR) la esmerada atención y el haber puesto a mi disposición sus depósitos documentales. 
Ernst Kantorowicz denomina cuerpo del rey ${ }^{2}$. Arte y propaganda se combinaban para transformar estas celebraciones, eminentemente urbanas, en actos políticos de adhesión al servicio de la monarquía hispánica (Mínguez, "Fernando" 193-196).

Era necesario, además, transmitir tal motivación a los demás sectores de la población. ¿Cuál fue la estrategia? Implementar actividades de reconocida participación pública, entre otras, el paseo del estandarte real, las escaramuzas y representaciones teatrales, los fuegos de artificio y luminarias, las corridas de toros, danzas y comparsas enmascaradas. Lo anterior supone que el espacio brindado por el esparcimiento era utilizado para promover una visión del mundo específica, que podía ser utilizada para inculcar valores como el sincero amor y acatamiento al rey.

La lealtad de los súbditos de los inmensos dominios americanos se puso de relieve en el difícil trance que sufre la Corona española en la primavera de 1808, año de la ascensión al trono del príncipe Fernando, tras el motín popular de Aranjuez, a raíz del cual su padre, Carlos IV, fue obligado a abdicar. Fernando se proclamó rey. A lo largo de 300 años, las dinastías de los Austria (nombre con el que se conoce también a los Habsburgo españoles) y los Borbón, que gobernaron el conglomerado que fue dado en llamar las Indias Occidentales, lo habrían hecho desde la seguridad y firmeza de un trono que nunca conoció amenazas externas que lo cuestionaran fuertemente. Sin embargo, cuando Napoleón encierra a la familia real española en Bayona (Francia), depone a Fernando VII y lo sustituye como rey por su hermano José Bonaparte, en junio de 1808, el trono se tambalea y la sensación de pertenecer a una monarquía imperecedera hace crisis.

2 Durante la fiesta y jura de proclamación, la iconografía y la simbología debían exponer y dejar clara la relación política que adquiría el nuevo rey. De acuerdo con este argumento, la asociación que constituía el juramento era la forma como se fundían los lazos políticos de la sociedad del Antiguo Régimen. El juramento establecía un pacto entre los agentes sociales que lo hacían; de ahí que a este tipo de práctica jurídico-ideológica se le denominara sociedad pactista' (Colom; Frasquet; Kantorowicz; Landavazo). 
Así, al mismo tiempo que se enfrentaba a los invasores franceses, se convocaba a elección de diputados para gobernar en nombre de Fernando VII y redactar la primera constitución escrita de España y su imperio ultramarino. La debacle de la monarquía borbónica en 1808 significó, en suma, la desaparición del único referente de legitimidad trascendente conocido en el mundo hispánico. Esos acontecimientos fueron resistidos en la península ibérica y en sus colonias en América. Don Fernando de Borbón se convirtió, por pretensiones meramente políticas, en El Deseado, El Traicionado, El Escondido, entre otros muchos epítetos (Chust).

Emocionalmente presionados, los súbditos americanos afirman su lealtad inquebrantable al rey cautivo. De ahí que, probablemente, ningún otro festejo expresa con mayor elocuencia la lealtad de todas las ciudades y villas de las colonias hispanoamericanas, y por consiguiente en Costa Rica, a su monarca, como la jura por Fernando VII, el último Borbón que reinó en América. Los representantes de la Corona debieron sorprenderse por las manifestaciones nunca vistas de fidelidad al sistema político vigente y de sumisión al legítimo soberano, las cuales se suceden en un arco temporal que abarca desde agosto de 1808 hasta principios de 1809, y que dependiendo de la riqueza del lugar, podían ser fastuosas o sencillas (Rojas 15).

Celo semejante sólo exhibió la autoridad eclesiástica al hacer cumplir con las cosas de Dios. Monarquía y religión, he aquí las bases fundamentales del absolutismo. Unidad, en fin, político-religiosa, fundamentada en la adhesión a los valores de una monarquía concebida como una "monarquía católica” (Chavarría; Guerra; Valenzuela). Por ello, en todos los actos públicos era denominador común la celebración religiosa, ya que invocar a Dios se identificaba como una forma de redención hacia el monarca.

En el caso de la Provincia de Costa Rica, circunscrita al Reino y Capitanía General de Guatemala ${ }^{3}$, sus habitantes, hombres y mujeres, vecinos

3 En cuanto a la justicia, a lo político y a lo militar, la Gobernación de Costa Rica pertenecía a la Real Audiencia y Cancillería de Guatemala; en lo religioso, Costa Rica dependía del Obispado de León de Nicaragua. La primera demarcación de la Provincia de Costa Rica correspondía 
principales y del común, esclavos y sirvientes, eran súbditos del rey español y, por lo tanto, debieron adecuarse al rito festivo que estipulara la autoridad monárquica de turno. Aparte de la jura de un nuevo monarca, se debían festejar otros eventos contingentes, como los esponsorios del rey, el nacimiento del primogénito y de toda la prole, la alianza con otra monarquía, los onomásticos reales o los nombramientos de gobernadores. El ciclo festivo se cerraba con los lutos sumamente rigurosos por el rey muerto $y$, una vez cumplidos con estos, se celebraba la entronización del heredero, con el grito ritual: “iEl Rey ha muerto, viva el Rey!” (F. Fernández cap. 4; Guevara). Las festividades combinaban rituales religiosos, políticos, militares y variadas diversiones públicas. Ellas podían expresarse bien en gestos protocolares o en una representación teatral, en un sermón eclesiástico, en una pomposa procesión urbana o en la iluminación nocturna obligatoria (por varios días) de todas las casas de la ciudad.

Así mismo, las festividades — conocidas como fiestas tradicionales o del "Antiguo Régimen" — incluían expresiones artísticas efímeras, como tablados, arcos triunfales y máquinas de fuegos artificiales ${ }^{4}$. En tales ocasiones, la Plaza Mayor o Principal era adornada de acuerdo con las circunstancias, y de noche era iluminada con antorchas para que se pudiera disfrutar de los festejos durante más horas. Las autoridades políticas y las familias principales eran los actores principales y el resto de la

a capitulaciones que databan de las postrimerías del siglo XVI, las cuales se mantuvieron sin mayores cambios hasta después de la independencia, en 1821. El territorio de la provincia, se extendía desde el río Tempisque, en la región del Pacífico Seco, y el río San Juan, en la zona del Caribe norte, hasta la isla del Escudo de Veragua, en Bocas del Toro por el lado del Caribe; y hasta el río Chiriquí, en el litoral del Pacífico. No obstante, aunque estas fueron las fronteras jurídico-administrativas de la Gobernación de Costa Rica, el dominio efectivo de los españoles asentados en Cartago era un espacio muy reducido que se circunscribía principalmente al Valle Intermontano Central, la región del Pacífico seco y, en forma más precaria, a los feraces territorios del Valle del Reventazón hasta el Caribe Central y la región del Pacífico Sur. Para ampliar consúltese Solórzano.

4 El modelo de fiesta que se inaugura en la América independiente utilizó, como paradigma, las fiestas profanas o regias que acaecían hasta en los sitios más recónditos, para legitimar sus nuevas estructuras de poder. 
población era principalmente espectadora y receptora del mensaje consciente e inconsciente (Garrido 17). El espíritu de fiesta colectiva, que ligaba a los súbditos al rey distante, habría sido de esta forma recreado a través de fórmulas mínimas comunes a todo el Imperio hispánico en América (Breña).

En este trabajo abordamos cómo se desarrolló la fiesta de proclamación y jura del rey Fernando VII en la ciudad de Santiago de Cartago, en $1809^{5}$, capital de la Gobernación de Costa Rica durante más de 250 años y ciudad regente de cuanto acaeciera en la provincia, la más "marginal" y "alejada" de la capital del antiguo "Reyno de Guatemala". Esta situación, no está de más señalarlo, imponía severas restricciones a la vida económica y social de la Provincia de Costa Rica. Así mismo, interesa valorar como veta historiográfica una antropología de los rituales del poder, a partir del estudio morfológico de la fiesta regia en la sociedad colonial cartaginesa. Poder y fiesta se hallan de este modo en el centro de nuestras preocupaciones. El análisis del poder exige un reconocimiento de las formas en que este se expresa - a través de fiestas, rituales y ceremonias - en la vida social no como una mera máscara o un pomposo adorno simbólico y estético, sino como un elemento fundamental que lo constituye. El poder, en suma, lo es porque se despliega mediante actos enfáticamente performativos ${ }^{6}$.

Desde épocas inmemoriales, la práctica festiva ha acompañado la vida en sociedad. ¿Qué es una fiesta? En latín, festa significa reunión para expresión de alegría. La fiesta es uno de los espacios más frecuentes en la

5 A mediados del siglo XVIII y principios del XIX, los vecinos de la ciudad de Cartago y su periferia festejaron el ascenso al trono de los siguientes monarcas de la dinastía borbónica: Luis I (1725), Fernando VI (1747), Carlos IV (1790) y Fernando VII (1809). Consúltese al respecto: R. Fernández (45-54).

6 Georges Balandier expresa contundentemente: “... tras cualesquiera de las disposiciones que pueda adoptar la sociedad y la organización de los poderes encontraremos siempre presente a la 'teatrocracia' $[\ldots]$ los actores políticos deben pagar su cotidiano tributo a la teatralidad $[\ldots]$ Todo sistema de poder es un dispositivo destinado a producir efectos, entre ellos los comparables a las ilusiones que suscita la tramoya teatral" (16). 
práctica ritual de la representación simbólica. Sus ritos ceremoniales y su lenguaje simbólico reflejan el imbricado tejido de las relaciones que se establecen entre los actores en un determinado ordenamiento social (Backzo; Bajtin; Ferrer; Garavaglia; Garrido; Gil; Gonzalbo; González; Martínez; Page). No hay que pasar por alto el carácter colectivo e integrador de la fiesta, ya que en ella participan los notables, las instituciones y la gente del común. De ahí que la fiesta se erija en un instrumento dinamizador del ideario de representación y teatralización del poder, y también para la comprensión de las prácticas cotidianas. Verónica Zárate ha escrito que las fiestas rompen lo cotidiano, "no reflejan una separación clara entre lo civil y lo religioso, entre lo profano y lo reverente, entre lo público de la celebración y lo privado de los sentimientos" (230).

Según la información documental disponible, la fiesta regia fue una ocasión especial para que los costarricas — gentilicio usado desde mediados del siglo XVIII hasta las cuatro primeras décadas del XIX — dieran pruebas contundentes de su aceptación, amor, obediencia, en fin, apego indiscutible al rey, percibido como la "cabeza" legítima del imaginario monárquico durante el régimen colonial. Los costarricas, al igual que muchos súbditos hispanoamericanos, demostraron su fidelidad y devoción a la monarquía ibérica, al otorgar su socorro económico a las milicias que defendían a España de la agresión francesa. Como recompensa a este gesto, el 16 de octubre de 1813, la ciudad de Cartago recibió el título honorífico de Muy Noble y Muy Leal. ¡Premio a los buenos vasallos, por su acendrado patriotismo! Así, es indiscutible que hasta el momento en que se presentó la situación imprevista de la independencia en 1821, nadie en Costa Rica cuestionó la institución de la monarquía. No hubo ni movimientos juntistas que reasumieran el poder soberano ni guerras por la independencia.

Por el contrario, el 30 de mayo de 1821, los costarricas celebraron el onomástico de Fernando VII, considerado por ellos como el "mejor de los reyes” (Quesada 151). La fuente principal para el estudio de la fiesta por la jura y proclamación del rey Fernando VII se encuentra en el minucioso 
documento/crónica elaborado por la pluma del procurador síndico general don Hermenegildo de Bonilla y Morales, en 1809. La "Relación de las funciones hechas en Cartago en proclamación de Fernando VII", fechada el 19 de junio de 1809, consta en el expediente 336 (del folio 153 al 157 v.) de la Serie Municipal Cartago, perteneciente a la Sección Histórica del Archivo Nacional de Costa Rica

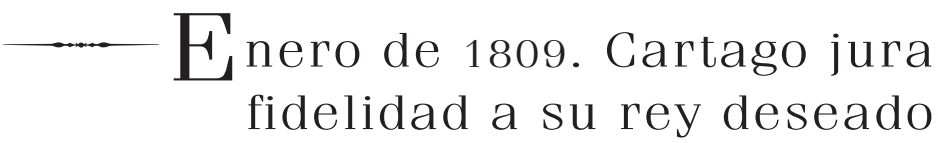

La ciudad de Cartago disfrutaba de una relativa tranquilidad cuando el 12 de septiembre de 1808 llegó la noticia procedente de la Real Audiencia y Capitanía General de Guatemala ${ }^{7}$ de que la Corona de España y de Indias había quedado en poder de Napoleón Bonaparte y sus tropas francesas. Desde el 14 de agosto de aquel año, la capital del Reino había repudiado con vehemencia tan infausto suceso, al tenor de sermones eclesiásticos, bandos de gobierno y actas de cabildo. Como no podía ser de otra manera, tan pronto como en Cartago se tuvo noticia de los sucesos de Bayona y de que España se encontraba bajo el control de Bonaparte, la reacción de los costarricas se desgranó, al igual que en otras latitudes americanas, en lealtad al joven rey y en repudio al emperador de los franceses.

En efecto, el sábado 17 de septiembre de 1808, el gobernador don Tomás de Acosta y Hurtado de Mendoza (abril de 1797 a 1809) convocóa

7 El Reino de Guatemala, una capitanía general pretoriana gobernada por un capitán general y una audiencia, estaba compuesto por lo que hoy día es Centroamérica, es decir: Guatemala, Honduras, El Salvador, Nicaragua y Costa Rica. Además, comprendía también al actual estado de Chiapas, el cual se anexó a México después de la Independencia. A pesar de que contaba con un territorio que era mucho más extenso que el de España, era la jurisdicción más pequeña del continente americano. Con aproximadamente un millón de habitantes —alrededor de 40.000 peninsulares y criollos, 313.334 castas (pardos y negros), 646.000 indígenas, que vivían juntos y mezclados en quince ciudades y villas de españoles, y más de 800 pueblos de indígenas y ladinos - fue la parte más densamente poblada de la América española. 
una Junta de Autoridades y a los "vecinos principales" ${ }^{8}$ de Cartago, con el fin de que en la Sala del Cabildo se discutieran las terribles circunstancias políticas por las que atravesaba la monarquía. A pesar de la lealtad demostrada a la Corona, la situación desorientó a las autoridades del gobierno provincial. ¿Quién mandaba en España? ¿Quién, si es que había alguien, debía ser obedecido? ¿Qué debería hacerse? Después de escuchar diferentes criterios, se acordó en firme que ante el forzado retiro del monarca reinante por medio de las armas napoleónicas, se considerara dicho acto como ilegal e inadmisible. Por tal motivo, se decretó, con una intensidad rayana en el delirio y el entusiasmo, renovar el juramento de fidelidad al rey Fernando ("objeto y fin de la fiesta", al que se hace depositario de todas las virtudes y cualidades posibles, hasta el punto en que se llegó a la casi sacralización de su persona), y no admitir a ninguna autoridad extranje$\mathrm{ra}^{10}$. Y todavía hay otra prueba aún más contundente de la fuerza de los sentimientos de lealtad de los costarricas hacia el rey legítimo: el "Donativo Patriótico” entregado para colaborar en la financiación de la guerra contra el "Corso"11.

8 Expresión utilizada por los acaudalados y poderosos en el Cartago colonial para diferenciarse de las "gentes del común".

9 El Cabildo de la ciudad de Cartago fue la principal institución política de la Provincia de Costa Rica y estaba compuesto, en su totalidad, por los vecinos principales: hijos y nietos de conquistadores, inclusive descendientes de cinco o seis troncos familiares, de acreditada hidalguía (F. Fernández 60-62).

10 Encabezados por el gobernador don Tomás de Acosta, los conspicuos asistentes a la reunión en la Sala Capitular “... unánimemente dijeron que no reconocen ni reconocerán jamás los actos de cesión hechos en Bayona de Francia por el Rey nuestro señor Carlos Cuarto y sus altezas reales el príncipe de Asturias y los señores infantes don Carlos y don Antonio, porque los tienen por desnudos de toda autoridad y fuerza extrínseca, por violentos, ilegales y por nulos en derecho [...] En su consecuencia renovaron todos el juramento de fidelidad y á las leyes que rigen, prometiendo guardar unión y conformidad con los magistrados, para conservar ilesa nuestra sagrada religión y mantener el buen orden y la tranquilidad pública. Al mismo tiempo protestaron no admitir ninguna autoridad extranjera..." (ANCR, CC 991).

11 El 17 de octubre de 1808, el gobernador y capitán general don Tomás de Acosta publicó por bando la declaratoria de guerra de España al emperador Napoleón I Bonaparte, y el 20 de ese mismo mes, inició una recolección de donativos para colaborar en la financiación del esfuerzo bélico. Don Tomás de Acosta aportó la considerable cantidad de 100 pesos como muestra de 
A la reunión del 17 de septiembre sólo asistieron 27 individuos avecindados en la capital colonial, entre otros, don Tomás de Acosta, don Joaquín de Hidalgo, don Ramón Jiménez y Rodríguez de Robredo y don Manuel de la Torre y Jiménez. Obviamente, no eran los artesanos o campesinos pobres, ni los indígenas, tampoco los mestizos, menos los esclavos, los llamados a discutiry analizar la coyuntura política del momento. En oficio del 7 de octubre de 1808, el capitán general y presidente de la Audiencia de Guatemala, don Antonio González de Mollinedo y Saravia (1801-1811), comunicaba oficialmente a Tomás de Acosta la "espontánea" abdicación del rey Carlos IV y la orden de levantar pendones por su hijo, el serenísimo príncipe don Fernando de Borbón (ANCR, CC, 1102 y 1968).

La prestación del juramento de fidelidad al nuevo rey se vio obstaculizada por el hecho de que el Cabildo de Cartago no estaba funcionando, por falta de regidores, y no se podía disponer de fondos para sufragar los gastos de los festejos. El gobernador, preocupado ante la posibilidad de que Costa Rica terminara siendo la última de las provincias que jurara lealtad a Fernando VII, consultó repetidas veces a la Capitanía y Audiencia de Guatemala, sin obtener una respuesta diligente. Tal y como lo expresó Acosta:

... por más fervientes que fuesen los deseos de [esta autoridad] en que se verificase la Proclamación de nuestro amado Rey y Señor con las formalidades de estilo y debida solemnidad, se presentaba un reparo que obligó á retardarla. Este fue hallarse [...] el Ayuntamiento con las vacantes de todos sus empleados, existiendo solo el de Alcalde Provincial, por lo que se dudara á quien correspondía en tal caso hacer las funciones de Alferes Real, y el fondo que debía sufrir los gastos de la Proclamación, pues no habiendo en esta ciudad [de Cartago] quien lo pudiese decidir fue preciso consultarlo á la Superioridad. (ANCR, MC, ff. 153r-153v)

La organización y celebración de cualquier acontecimiento festivo demandaba una serie de egresos que en su mayor parte se sufragaban con

patriotismo y como ejemplo para sus gobernados. Para diciembre de 1808, se había recolectado un total de 215 pesos y 4 reales. La dádiva se depositaba en las cajas reales para que fuera remitida a España (Estrada 126). Además, véase: ANCR, CC919, 1818; MC, f. 169v. 
los fondos de las cuentas del rubro de "propios"12, sin discutir si por ello quedaban paralizadas las obras públicas (Guevara 92-93). Sin embargo, en algunas oportunidades, el gobernador debía costearlos de su peculio, como en efecto sucedió, pues fue Acosta quien sufragó los gastos de los festejos (ANCR, MC, f. 165), temeroso de que las tempranas y continuas lluvias los deslucieran. Pero quizá, en el fondo, había una cuestión de orgullo de don Tomás de Acosta, de probar ante sus gobernados su poderío, lealtad y acatamiento al rey.

Estas fiestas, que de su propio bolsillo costearon como muestra de un claro testimonio de "vasallaje, fidelidad, amor y obediencia" de cada súbdito a la figura todopoderosa que se tenía del rey, se prolongaron por espacio de nueve días: desde el 15 al 23 de enero de $1809^{13}$. El domingo 8 de enero de 1809, una vez subsanado cualquier reparo, un bando del gobernador Tomás de Acosta hizo público en Cartago el programa de las festividades que se habrían de iniciar una semana más tarde, donde se advertía "... que todos observasen solemnidad, pompa, buen orden, decoro y tranquilidad”.

A los fines de procurar la moderación y el orden en los espectáculos y diversiones, la Gobernación dispuso "cerrar los estanquillos" y "no vender una gota de aguardiente, bajo la pena de cinco pesos de multa” (ANCR, MC, ff. 117-118; CC 993 y 994). En este sentido, la legislación vigente resultó ser bastante drástica, por medio de ordenanzas que regulaban el comportamiento de los participantes, su indumentaria y el lugar que deberían ocupar en cada actividad. En los días festivos el ámbito urbano y sus protagonistas experimentaban cambios profundos en la ornamentación de los edificios, limpieza de calles, vestimentas especiales e, incluso, en la ejecución de una

12 Fondos municipales provenientes básicamente del alquiler de tierras que permanecían bajo la administración del Cabildo.

13 En el fondo, esta muestra de esplendidez del gobernador don Tomás de Acosta se debió a que la consideraba una inversión provechosa que se recuperaba en forma de respeto popular y consolidación del poder. 
arquitectura efímera construida para la ocasión. De esta suerte, los vecinos de Cartago, distinguidos o no, debían ataviar e iluminar las puertas y ventanas de sus viviendas, talar los árboles de güitite ${ }^{14}$, encalar los edificios principales y arreglar el tejado de estos, limpiar las calles y plazas, colocar arcos adornados con flores, palmas y ramas de uruca ${ }^{15}$ y poner pretiles a las acequias; amén de vestir las mejores galas. Inmediatamente después, la Gobernación indicó a la oficialidad del Batallón, a los dependientes de la Real Hacienda y a los vecinos de los "lugares inmediatos" del Valle Central que les correspondía hacerse cargo de un día de funciones (ANCR, MC, f. 123).La lejanía geográfica respecto a los principales centros virreinales y a la Audiencia de Guatemala no era óbice, sino más bien acicate, que impidiera la realización de la fiesta. Indudablemente, las festividades más sonadas estarían auspiciadas por la Gobernación y por las familias cartaginesas más opulentas y las consideradas de origen español. Además, en el mundillo de las representaciones sociales, los vecinos y las vecinas principales de Cartago eran los depositarios de las prebendas que gozaba una ciudad capital (Moya 174-175), y los capitalinos no disimulaban su desdeño hacia los advenedizos que habitaban el sector occidental del Valle Central de Costa Rica. Ante un evento de tal envergadura, don Tomás previno tajantemente a sus gobernados para que en la jura del Rey,

... todos los vecinos estantes y habitantes en esta ciudad [incluidas varias familias principales de Cartago] ... que en todo tiempo dedicado al consabido fin, suspendan los lutos que tuviesen; y que antes por el contrario, manifiesten con gala los sentimientos de alegría que mueven nuestros corazones á la mayor delicia, en actos tan debidos al Soberano, nuestro principal objeto. (ANCR, $M C$, f. 121)

Como se habrá advertido, se trataba de una celebración atrasada que pretendía, según regia disposición, festejar la ascensión de don Fernando VII al trono español, demostrarle apoyo y reafirmarle el aprecio y la estima

14 Güitite (Acnistus arborescens D C) (Gagini, 106).

15 Uruca (Trichilia havanensis) (Gagini 204). 
mientras estuviera prisionero en tierra extranjera. Por eso, a fuerza de demostrar su lealtad al distante e incuestionable rey, el gobernador Acosta se empeñó en llevar adelante la jura de su obediencia, aunque fuera tardía, y la demostración de su encono a Napoleón. Así, la principal autoridad en el territorio de la Provincia de Costa Rica y de su capital se empeñó en crear un ambiente festivo impuesto, producto de la contingencia. La población se reunió en torno a la celebración de la Gobernación colonial cartaginesa, la que se encargó de que todo cuanto aconteciera en las reales fiestas fuera anotado. Un dato importante es que en la época en que se realiza la real jura a Fernando VII, la ciudad de Cartago y sus arrabales contaban con poco más de 12.000 habitantes, y toda la provincia, con unas 50.000 almas (Pérez 24). Si la asistencia del público en los días de mayor solemnidad fue masiva, probablemente participó un $25 \%$ de esa población, de la cual los vecinos y vecinas distinguidos no debieron ser más de 600 sujetos.

¿Cómo era la fisonomía del Cartago colonial en los albores de la centuria decimonónica? ${ }^{16}$. A principios del siglo XIX, la ciudad de Cartago — cuyo asentamiento definitivo en el Valle de El Guarco data de 1575 — ${ }^{17}$ no había escapado a la simetría impuesta por las Leyes de Indias y mantenía las mismas características de otras ciudades españolas fundadas en América: se inscribía en el tipo de ciudad trazada en cuadrícula o damero, forma del tablero del juego de "damas", a la usanza española, que permitía una organización clara y simple de los elementos cívicos, ya fueran religiosos o político-administrativos. En este microcosmos colonial, aldeano, conservador e infundido de una fuerte raíz católica, la solemnidad de las funciones religiosas no eclipsó, de ninguna manera, las celebraciones

16 Para analizar el proceso de ocupación étnico-espacial de la ciudad colonial de Cartago y sus alrededores, véase: Acuña y Chavarría.

17 La ciudad de Santiago de Cartago, antigua capital de Costa Rica, fue fundada en 1564 en un valle plano y arcilloso, ubicado en las faldas del volcán Irazú, y cerca de la confluencia de los ríos Taras, Coris y Purires. Las constantes lluvias convertían a la incipiente ciudad en un campo de lodo. En 1575, después de múltiples vicisitudes y traslados, fue reasentada en el sector noreste del Valle de El Guarco, donde hoy día se encuentra. Para mayores detalles véase Solórzano y Quirós (cap. 6). 
profanas desplegadas en el espacio urbano del Cartago de principios del siglo $\mathrm{XIX}^{18}$.

El espacio abierto de la Plaza Mayor, el atrio de la Iglesia Parroquial del Apóstol Santiago o Vicaría de Costa Rica, sus escalinatas, los ediffcios que la rodeaban y las calles que allí desembocaban cumplían cada uno con una función en el desarrollo de la fiesta ${ }^{19}$. ¿Con qué funciones y regocijos se elogiaba a Fernando VII? La noche del 14 de enero de 1809, víspera de la proclamación del rey, hubo repique general a vuelo en todas las iglesias de la ciudad de Cartago, salvas de artillería, completa iluminación, gran número de cohetes, mascaradas, desfile de faroles y música por las arterias centrales, las cuales estaban limpias y acicaladas. Calles y plazas, solares de edificios públicos, iglesias o viviendas... Todos son espacios aptos para convertirse en lugar del espectáculo. Como bien puede suponerse, las festividades servían de pretexto para dar rienda suelta a los sentidos y las autoridades debían estar pendientes de tomar todas aquellas medidas conducentes a evitar el desorden. Esto queda evidente en la siguiente citación:

18 El espacio para socializar, aparte de la misa, el mercado y las fiestas sacras y profanas, era limitado. En efecto, en las casas particulares se podían barajar cartas, jugar al truco (billar) y a las tablas (dados), o gozar de una tranquila velada, al calor del vino y el aguardiente, o de un sabroso chocolate en jícara labrada. Para ampliar véase: F. Fernández (cap. 4) y Guevara (48-183).

19 La colonial ciudad de Cartago, a pesar de sus dimensiones modestas, se lee como un texto y revela un uso jerárquico de los espacios que contiene. En el centro se ubicaba la Plaza Mayor y la Santa Iglesia Parroquial, la de mayor rango de la provincia; hacia el noreste de la plaza se ubicaban las casas del Cabildo o Ayuntamiento y la cárcel, modestas construcciones de paredes de adobe y techos de teja, y hacia el sureste el cuartel de las milicias. El cementerio parroquial se ubicó en el cuadrante noreste de la Iglesia Parroquial. En los distintos cuadrantes de la ciudad, no muy lejos de la Iglesia Parroquial del Apóstol Santiago, y como quien dice flanqueándola, se ubicaron al menos seis iglesias, que por cierto no se encontraban en las afueras de la ciudad, sino a escasas cuadras de la Plaza Mayor o Principal. Entre las iglesias de mayor categoría sobresalían la de San Francisco, con su convento anexo, a tan sólo dos cuadras al sur de la Plaza Mayor, y la dedicada a la Virgen de la Soledad. La ermita donde se le rendía culto a la imagen negra de la Virgen de los Ángeles se encontraba en el límite este de la ciudad, al abrigo de la "Ls Gotera de Cartago" o "Puebla de los Pardos" y alejada del espacio habitado por el elemento de origen español (Brenes cap. 2; Moya 175-176). 
... Para que $[\ldots]$ hubiese el orden debido, dio el Gobernador las providencias correspondientes para que no faltasen Patrullas y Rondas en la Ciudad y sus arrabales; así se consiguió que en los nueve días de continua diversión no hubiese el menor motivo para corregir á ninguno, ni siquiera arrestarle. (ANCR, MC, ff. 154r-154v)

El día 15 de enero de 1809 fue el más solemne. Dado que era importante sacralizar el $\mathrm{acto}^{20}$, a las nueve de la mañana, con todo el venerable Estado eclesiástico, se celebró una misa cantada de acción de gracias en la Iglesia Parroquial, en la cual se expuso el Santísimo. A ella asistieron el gobernador don Tomás de Acosta; los alcaldes ordinarios don José María de Peralta y La Vega y don Nicolás de Oreamuno y Sancho de Castañeda; el síndico procurador o "Representante del Común", don Hermenegildo de Bonilla; el alcalde provincial don Manuel de Marchena y Vargas Machuca; los jefes y oficiales del Batallón Provincial; los miembros de las familias principales de Cartago, y los otros agentes sociales convocados por el bando del gobernador. A estos últimos se les coaccionaba a participar, de lo contrario, podía "castigárseles severamente como enemigos traidores de la Real Corona" (ANCR, CC 5339, ff. 1r-1v). A las puertas del templo de Santiago, se encontraba formada la Compañía de Granaderos, capitaneada por don Joaquín de Oreamuno y Muñoz de la Trinidad, a la sazón, alguacil mayor y vecino principal de Cartago. En la esplendorosa liturgia sacramental, fray Manuel de la Horta ${ }^{21}$ pronunció un largo sermón religioso-político, en el que hinchió al "Rey Deseado" de elogios, y que terminó invocando la protección divina, junto a las ideas del pactismo social entre rey y vasallos. La lealtad al rey es inseparable de la adhesión a la religión (ANCR, MC, ff. 124r-130v).

Es indudable la pretensión legitimadora y propagandística de la autoridad del monarca español a través del sermón religioso. Dentro del culto católico, el acto central de la misa lo constituye el sermón y el tedeum es gura un espacio simbólico signado por lo religioso.

21 Franciscano. Misionero apostólico del Colegio de Cristo Crucificado de Guatemala. 
un agradecimiento al Creador, que forma parte del acto sacramental, cuyo testigo es Dios. La misa y el juramento corresponden a la visión tradicional del poder emanado de Dios; quienes lo detentan son responsables ante Él. En este ambiente en que lo sagrado y lo cívico se confunden, las autoridades coloniales se presentaban al templo para dar gracias y recibir la protección del Todopoderoso; por su parte, la Iglesia católica recibía un reconocimiento como institución y mediadora divina (Martínez 99). La Iglesia Parroquial del Apóstol Santiago debía estar completamente iluminada en el interior de todas sus naves y adornada con la magnificencia que exigía el acontecimiento.

En el principio, intermedio y fin de la misa se hicieron salvas por parte de la Compañía de Granaderos. Debe considerarse que respecto a la concurrencia a la liturgia, no hay distinción entre los agentes sociales; sin embargo, la élite colonial cartaginesa ocupaba el espacio interior de principal jerarquía cerca del altar mayor, mientras que el resto de la multitud ocupó los ámbitos y extensiones del templo. El asunto no terminaba allí. En esta disposición del espacio del templo también se tomaba en cuenta la forma en que se había llegado hasta el sitio y con la que se saldría de él. Los distintos cuerpos se presentaban con una vestimenta especial, que exhibía rango y circunstancia. Después de la solemne misa mayor y del tedeum laudamus, el gobernador Acosta ofreció en su casa refrescos, mistelas y dulces ${ }^{22}$; y de seguido, un banquete ${ }^{23}$ al calor de la música de los indígenas danzantes de las reducciones o "pueblos de indios" de Cot, Quircot, Tobosi y el Naborío.

Ya en la tarde, alrededor de las cuatro, se llevó a cabo el rito supremo de la fiesta: el juramento de fidelidad y la teofanía real. Don Tomás de Acosta recibió de don Manuel de Marchena la bandera del Batallón Pro-

22 Los refrigerios que se acostumbraban servir al concluir las actividades matutinas incluían tanto refrescos elaborados con el zumo de distintas frutas como las bebidas espirituosas. La mistela era una bebida hecha con aguardiente, mezclado con dulce y canela. Véase Ross (88).

23 Para una explicación amplia sobre el significado del banquete, véase Bajtin (cap.4). 
vincial, y se inició un solemne desfile militar por las calles alrededor de la Plaza Mayor. Dentro de la simbólica del poder colonial, el paseo del pendón real o estandarte representaba un homenaje hacia la autoridad regia; en fin, una manera de patentizar obediencia, lealtad y respeto al poder instituido (Guevara 104).

Cuando no se contaba con el real lábaro, se acostumbraba hacer el despliegue de la bandera en las manifestaciones públicas, tal y como lo dispuso don Tomás de Acosta en 1809, "tanto por ser la insignia que hemos de seguir á defender de los enemigos, quanto porque estando ya bendita se omitía esta ceremonia" (ANCR, MC, f. 154). A la cabeza del desfile, marchaba el portero del Cabildo, el Batallón, los caballeros que formaban dos hileras que cubrían ambos lados de las calles y, por último, cerrando la escolta, el gobernador con el alcalde primero y el señor coronel. Hacían parte del cortejo las justicias de los pueblos de indios, que animaban con sus instrumentos y atuendos especiales (ANCR, MC, f. 127).

La puesta en escena de los poderes se representó en el desfile, en el cual figuraban las autoridades de la Provincia de Costa Rica y de los distintos pueblos indígenas colindantes, las compañías del Batallón, las bandas militares y los vecinos de distinción. Mas la plebe, como comparsa, también participó del evento, ubicándose en el espacio reservado por la costumbre. El orden en que cada uno de los actores sociales desfilaba había sido asignado previamente por mandato de la Gobernación. Probablemente, este precepto obedecía al interés de las autoridades de que no quedaran dudas de los sentimientos de fidelidad y adhesión de los grupos subalternos hacia el régimen monárquico, representado por ellas, quienes desde su posición de cierre del desfile reafirmaban, en los espectadores, su obligación de doblegarse dócilmente al soberano español.

En fin, un orden establecido que rendía culto a la monarquía, pero también a la estratificación social y étnica como soporte de las diferencias locales. Los signos festivos informan acerca de las relaciones sociales. Por ello, allí se podían observar tanto la unidad como la diferencia. Unidad que en el imaginario del Antiguo Régimen significaba la centralidad del poder 
monárquico, manifestación de lealtad, exaltación de la nación española. Diferencia en cuanto a los privilegios, las posiciones, la participación reglamentada, controlada y jerarquizada. Es sabido que todas las ceremonias públicas del Antiguo Régimen tienden un puente en el espacio entre el centro de poder político y otro religioso. Consecuentemente, ¿cuál fue el espacio cívico y tangible donde se celebró el desfile? El recorrido de la procesión por la capital colonial fue el siguiente: hacia el este, por la Calle Real o de la Sacristía, pasando por la calle llamada de doña Encarnación Trinidad; luego el desfile se dirigió hacia la derecha, por la calle de San Francisco. De allí, se continuó por las calles del Vía Crucis hasta la Iglesia de San Nicolás y, por último, los viandantes se dirigieron de nuevo desde la Calle Real hasta la Plaza Mayor (ANCR, MC 336, f. 154-157).

En la Plaza Mayor se alzaba un tablado o estrado cubierto con un dosel, desde el cual el alcalde Peralta y el coronel del Batallón, don Juan Francisco de Bonilla y Morales, "Reyes de Armas", por designación del gobernador, daban jubilosamente los gritos de: “¡Cartago, Cartago, Castilla y las Indias por don Fernando VII!”. La jerarquía de pertenencia está muy clara: la Corona (Castilla), el reino (las Indias), la ciudad (Cartago). Seguidamente, Acosta pronunció el solemne juramento de fidelidad. El gobernador repetía la fórmula por tres veces desde diversos ángulos del estrado, al mismo tiempo que hacía "tremolar" el real pendón ${ }^{24}$. Las demás autoridades contestaban "Amén” y, al unísono, las gargantas de los colonos cartagineses pronunciaron la sencilla frase ritual, para manifestar de ese modo la aceptación del monarca.

Sin duda alguna, las vivas de la multitud constituían la expresión oral de entusiasmo y adhesión al poder monárquico. Si bien los funcionarios de

24 El pendón era una bandera o estandarte pequeño, de carácter militar, más ancho que largo. Se usaba en todas las actividades relacionadas con la monarquía. El alzamiento y tremolación del pendón real era un rito fundamental, realizado en todos los rincones urbanos del Imperio colonial español. La manipulación ritual del pendón para estas ocasiones se insertaba en el juego metafórico del renacer de la monarquía. 
la administración colonial desfilaban por las calles, finalmente se situaban en el tablado, en representación de su autoridad. Las autoridades y notables eran colocados por encima de los espectadores que reconocían y aceptaban su potestad, lo que reafirmaba la pertenencia a la Corona española.

El tablado constituía una importantísima parte del festejo. Colocado en el centro de la Plaza Mayor, rodeado de gradas y profusamente decorado con telas vistosas, flores, palmas y adornos diversos, debía lucir como un gran cuadro vivo, gracias a la animación que le proporcionaba el público con sus actuaciones. Es posible visualizar la escena como una verdadera apoteosis ante la imagen del regio personaje y el significado virtual que tenía para los presentes, además de lo ensordecedor de esta. Tras el juramento, se arrojaron "muchos puñados de dinero" ${ }^{25}$ al público entusiasmado, entre el tronar de la fusilería y el tañido de las campanas (ANCR, MC, 154-157).

Este acto, de innegable impacto en la muchedumbre, debió de ser un acontecimiento memorable, no sólo para aquellos afortunados que lograran recoger alguna de las monedas que se les ofrecían con liberalidad, sino también para todo aquel que presenciara una escena de connotaciones evidentemente sociodramáticas. Era un rito que permitía, en fin, incitar la continuidad de los gritos y aplausos de los espectadores. Además, su importancia se verá realzada si se tiene en cuenta la escasez de metálico que sufría la "marginal" y alejada Costa Rica (Chacón 32-3). El homenaje de la ciudad se mudaba, simbólicamente, en un pronunciamiento de lealtad al rey.

Mientras la gente vivaba a Fernando VII, se efectuaba, con el despliegue del estandarte del Batallón, un desfile alrededor de la Plaza Mayor, el cual concluyó en la sede del Cabildo de Cartago. Acto continuo, don Tomás de Acosta convidó a los selectos concurrentes a un "delicado refresco de cuanto franquea el país", y a eso de las siete de la noche en la misma plaza inició una función de fuegos de artificio, que no podían faltar en estas celebraciones. Se presentaron varias figuras alusivas que ardieron dando luces

25 Posiblemente, se trataba de monedas de plata de un real. 
multicolores. Tal fue el caso de un "famoso castillo" de cuatro cuerpos que fue quemado, en cuya parte superior se mantuvo encendida durante varios minutos una consigna que decía: “¡VIVA EL REY FERNANDO VII!”, novedad muy aplaudida. Para finalizar, alrededor de las diezy media de la noche, se iluminó una corona con dos banderas a sus lados, una con el escudo de las armas reales y la otra con el de la ciudad de Cartago.

Con las luminarias y los fuegos artificiales se pretendía dar a las noches el brillo que durante el día la luz del Sol prodigaba al decorado urbano. Muy elocuente es el hecho de que, durante toda la noche y a la luz mortecina de las velas, estuvo abierta la Sala Capitular donde estuvo expuesto el retrato de su majestad, acompañado de un regimiento de honor. Y, por extraño que pueda parecer, toda la madrugada los vecinos de Cartago llegaron hasta el recinto, con el fin de rendir "culto" a la áulica imagen borbónica. Probablemente, la gente se acercaba a la efigie y le hablaba: unos para consolarlo, otros para darle ánimos y otros más para fulminar rayos contra Napoleón y los "impíos" franceses. Dicho acto es, por supuesto, de carácter ritual y simbólico ${ }^{26}$. Al respecto, como bien lo expresa el historiador Roger Chartier: "... la representación se transforma en una máquina de fabricar respeto y sumisión, en un instrumento que produce una coacción interiorizada, necesaria allí donde falla el posible recurso a la fuerza bruta" $(69)^{27}$.

El lunes 16 continuaron los festejos. En la mañana, después de dispararse cohetes y tocarse diversas piezas musicales, se efectuó un apretado desfile, por las calles de Cartago, con los toros bravíos que habrían de correrse por la tarde, a cuyo término, don Tomás de Acosta ofreció un bufé en su residencia. A eso de las tres de la tarde, se presentaron en la Plaza Mayor las máscaras, "diabladas" o "mojigangas", en las que participaban, habitualmente, los indígenas (Guevara 65). La participación de los indígenas danzantes puede interpretarse como una manifestación de su

26 Estos aspectos se pueden ampliar en Gayol; Landavazo (59-221); Martínez; Mínguez ("Fernando" 193-196).

27 Puede verse, además, el trabajo de Gruzinski (146). 
"lealtad" a la monarquía hispánica y una oportunidad de expresar públicamente sus tradiciones e identidades.

Inmediatamente después de las mascaradas se inició la corrida de toros. En el toril — ubicado en la Plaza Principal, ya que no existían lugares construidos específicamente para este tipo de espectáculo — se hacían presentes desde las más altas dignidades civiles y eclesiásticas hasta los mestizos, españoles pobres, negros, mulatos, pardos e indígenas, todos quienes participaban con gran alegría. Sin ninguna duda, la fiesta taurina servía de solaz tanto para los que participaban en las faenas de a pie como para aquellos personajes más conspicuos que se regocijaban haciendo alarde de sus mejores caballos y sillas de montar — amén de demostrar su riqueza, fuerza y destreza ecuestre-; aunque no faltaban los aficionados, quienes lo hacían montando sus humildes jamelgos (Fernández, La Plaza 76-77).

Llegada la noche, el gobernador ofreció un sarao amenizado por dos bandas musicales. Al baile concurrieron, en pleno, las señoras y sujetos distinguidos de Cartago, vestidos con sus mejores indumentarias. Riquísimos tejidos, colores, joyas y aderezos que, al tiempo que manifestaban la solvencia económica de los vecinos y damas principales, revelaban la representatividad de los portadores. El arreglo de la casa del gobernador, visible sólo para la Élite colonial cartaginesa en pleno, fue el siguiente: “... sala bien iluminada [... ] y todo con el mayor aparato, orden y simetría”. A la medianoche se sirvió una cena o "ambigú" compuesta de manjares calientes y fríos. Como se habrá advertido, la ingesta de alimentos y bebidas era un elemento muy importante, que acompañaba todas las celebraciones del poder. El baile se extendió hasta las tres de la madrugada del martes (ANCR, MC, f. 156).

A partir del martes 17 de enero, el Batallón Provincial tomó a su cargo los festejos, y se realizó el acostumbrado desfile callejero con toros, y en la tarde, se verificó la lidia. La corrida de toros, con gran asistencia de público, fue dirigida por el capitán don Joaquín de Oreamuno, debido a la ausencia fortuita del gobernador. Otro tipo de espectáculo escenificado en la Plaza Mayor era el que consistía en un simulacro bélico, de origen 
señorial/medieval, que enfrentaba ejércitos, con frecuencia de "Moros y Cristianos", también llamado "morismas", o que enfrentaba a indígenas contra españoles. En la escaramuza organizada en Cartago, en ese mismo día, participaron cuatro cuadrillas compuestas de mestizos y "gentes de color" (negros, mulatos, zambos y otras castas) ${ }^{28}$, dos vestidas a la usanza española, y las otras, a la "amazona".

Tamaño espectáculo a veces incluía también elementos de escenografía efímera, como galeras móviles y castillos (Calderón 20-25). Al anochecer, se llevó a cabo un nuevo baile para los notables, con cena incluida, que se consumió a las tres de la mañana del jueves. Las fiestas reales continuaron en los siguientes días y su desarrollo se confió a los vecinos de las otras tres poblaciones principales del Valle Central de Costa Rica: Villa Vieja (la actual Heredia, 1714), Villa Nueva (la actual San José, 1737) y Villa Hermosa (la actual Alajuela, 1782) (ANCR, MC, ff. 156v-157r) ${ }^{29}$. Los vecinos pudientes de la Villa Nueva se encargaron de las festividades del 19. El día 20, la fiesta estaba destinada a los vecinos de Villa Vieja, la del 21 estuvo a cargo de los vecinos de la Villa Hermosa ${ }^{30}$. Todavía el domingo 22 de enero de 1809, siguieron las fiestas en Cartago. Los veteranos del Batallón

28 Para celebrar la jura de Fernando VII, "quatro cuadrillas de mestizos y gentes de color no pudiendo costear ninguna $[\ldots]$ función en obsequio del Soberano pidieron se les permitiese [hacer esta escaramuza] en demostración de su regocijo y respetuoso amor" (ANCR, MC, f. 155v).

29 Sobre el surgimiento de las ciudades de San José, Heredia y Alajuela, véase Meléndez; C. Molina (455-462).

30 Los días más solemnes de la jura del rey Fernando VII estuvieron bajo el auspicio del gobernador don Tomás de Acosta, y el resto, como quien dice los días menos representativos, estuvieron bajo el patrocinio de los principales vecinos de Villa Hermosa, Villa Vieja de Cubujuquí y Villa Nueva de la Boca del Monte. En las fiestas del 19 de enero de 1809, encomendadas a los notables de Villa Nueva, hubo desfile taurino, torneos y escaramuzas, y corrida de toros; y por la noche, un baile que duró hasta la madrugada. El 20 le tocó el turno a las autoridades de la Villa Vieja, quienes repitieron el desfile de toros y demás, pero cuyo sarao, acompañado de una comida espléndida, se prolongó hasta el amanecer. Las fiestas del 21 , a cargo de los vecinos de Villa Hermosa, no modificaron el programa de los días anteriores, y su baile llegó hasta las luces del alba (ANCR, MC, ff. 156r-156v). 
Provincial se encargaron de realizar otra vez desfile con toros, espectáculo, corrida y sarao.

Las actividades que se produjeron estaban íntimamente ligadas con el rito que les dio inicio: la jura. Cada grupo social expresó, a través de distintas formas, su adhesión a la Corona, y con ello demostraba su inquebrantable lealtad al monarca preso en Bayona. En teoría, el escenario festivo pertenecía a todos y todos podían convivir en él, pero en la realidad lo hacían bajo el ojo vigilante de las autoridades y con una separación bien marcada.

Para clausurar el estado de fiesta y dejar sellada la lealtad a Fernando VII y el odio a Bonaparte, en un tablado erigido frente a la Sala Capitular, el cual se encontraba bien iluminado y revestido de cortinajes, se realizó en la noche del 23 de enero de 1809 una loa y un entremés o comedia, en los que se expuso, ante un numeroso concurso, un canto de alabanza al monarca legítimo y una imprecación al emperador de los franceses ${ }^{31}$. No cabe duda de que las representaciones escénicas provocaban un impacto visual muy importante ante una sociedad mayoritariamente iletrada. Justamente, el interés de tales actos radicaba en hacer visibles, a través de varios personajes, la legitimidad del reinado de Fernando VII y, consecuentemente, lo ilegítimo del de Bonaparte. El lenguaje utilizado reflejaba, además, la recurrencia a la divinidad como sostén del poder colonial e imperial. A modo de ejemplo, uno de los actores, disfrazado de soldado, arengó vehementemente mientras lo acompañaban los alegres acordes de la música de timbales, flautas, trompetas, violines y guitarras:

Novilisimos Señores/ de la Ciudad de Cartago/ bendecid á Dios en pago/ de que os hace mil favores/ Regocijad con agrado al Poderoso Criador que os ha

31 Don Joaquín de Oreamuno y Muñoz de la Trinidad, alcalde, alguacil mayor y regidor del Ayuntamiento de Cartago, escribió la loa No. 4 y los entremeses No. 5 y No. 6, que se representaron con todas las formalidades del caso, por un grupo de jóvenes distinguidos de la ciudad de Cartago (ANCR, MC, ff. 157). Para ampliar pueden consultarse el trabajo de Sáenz. La loa y el entremés teatral se reproducen en su totalidad en "Teatro Colonial". 
dado por favor la Rey que hoy habeis jurado/ A Dios por todo alabando siga la mucica y diga/ Que eternas edades viva/ nuestro invicto Rey Fernando/ No cesen los parabienes/ ni la gloria popular/por la diadema Imperial/ que hoy fixa el Rey en sienes/Viva nuestro Rey Jurado/ Fernando VII en modo que del universo/ sea aplaudido y exaltado/ en todo el orbe se diga/ con solo una voz y un bando/ triunfe y reyne don Fernando/ y eternas edades viva. (ANCR, MC, ff. 131r-152v)

Y, aún más resulta elocuente el entusiasmo y aplausos desbordados de las masas espectadoras cuando, en el clímax del entremés, se quema una grotesca figura que representaba al "pérfido" Napoleón. ¿Auguraría esta representación en la Plaza Mayor, convertida literalmente en un teatro, la caída del régimen napoleónico? Según narra vívidamente el cronista e historiador cartaginés Manuel de Jesús Jiménez Oreamuno (1854-1916) en el cuadro costumbrista "Fiestas Reales":

Al terminar el entremés resonaron en la Plaza de Cartago largo rato los aplausos, y en verdad que no eran infundados. El muñeco había ardido en grandes llamaradas y estallado el gran bombón de su cabeza. El Coloso había quedado desquiciado en Bailén y Talavera, y ya se veía en lontananza a Waterloo. (67)

Acompañaba, a la ya tan de por sí metafórica puesta en escena, el siguiente cuarteto, que a la letra dice:
Así como arde este fuego
arden los nobles vasallos
su amor y digan todos:
viva nuestro Rey Fernando.
(ANCR, MC, ff. 131r-152v)

Estas citas, espigadas entre muchas otras, además de poner de relieve el sentimiento de los vecinos de Cartago por su "Augusto Monarca", evidencian magníficamente el poder de las imágenes como instrumentos causantes de una catarsis colectiva, con un eficaz apoyo acústico y musical. El espectáculo estuvo asociado con el creciente fervor que invadía las almas de los fieles patriotas. Dentro de una estructura simbólica, la crónica reproduce el orden social. En torno al tablado se instalaron cómodos palcos y galerías para las rancias familias principales, y los individuos de baja 
condición social desbordaban los distintos puntos de la Plaza Mayor. No está de más reiterarlo: se trataba de una sociedad tradicional y diferenciada, donde los factores de prestigio y representación eran fundamentales.

\section{Conclusión}

En definitiva, a través de lo expuesto en este trabajo, se puede argumentar que las escenificaciones del poder en la sociedad colonial giraban en torno a dos grandes dispositivos estrechamente vinculados: la monarquía y la Iglesia católica romana. La fiesta tiene una fuerza ambivalente que provoca una fortísima tensión entre lo sagrado y lo profano. Así, la celebración y el gozo originados por el juramento de fidelidad incondicional al poder monárquico solían iniciar con un tedeum solemne, seguido de una procesión de funcionarios civiles y religiosos. El ámbito central de las festividades de 1809 fue la Plaza Mayor de Cartago, aunque compartido con la Iglesia Parroquial del Apóstol Santiago y el Cabildo, inseparables emblemas del poder hispánico. Poder que prácticamente quedó impregnado en el rito, el sermón y en la utilización del espacio durante las ceremonias.

La fiesta multitudinaria de aclamación al trono del rey Fernando VII posibilitó, por una parte, romper — por diversos que fueran los oficios y las experiencias - la habitual "vida monótona" de la capital de la Provincia de Costa Rica; por la otra, se constituyó en instrumento fundamental de un orden económico y social que se presentaba inamovible e inmutable. Según don Tomás de Acosta, los súbditos cartagineses estaban prestos “... á verter su sangre en defensa de la Religión que profesaban; del Rey que han jurado; y de su Patria que aman” (ANCR, MC, f. 117v). La lealtad y la obediencia hacia la "Religión, el Rey y la Patria" expresaba, en fin, un vínculo directo con Dios, la Corona y su Rey, y se refería a todos los dilatados dominios de la monarquía española.

Una fiesta del rango y solemnidad que significaba la reiteración de lealtad a un monarca forzosamente abdicado (pero cuya abdicación 
habían desconocido las autoridades peninsulares y locales, hay que recordar) alcanzaba, evidentemente, a todo el conjunto social y a individuos de toda condición. Es sabido que todo orden social se asienta, entre otras cosas, en un sistema de ritos y símbolos que son funcionales a la creación, consolidación y mantenimiento de dicho orden (Backzo 14-17). Por ello, aunque la presencia del Rey no gravitaba en la ciudad de Cartago de manera directa, su imagen era obligatoria en las ceremonias festivas que día a día se sucedían: desde el consabido tedeum hasta el paseo por las calles de la ciudad de Cartago, y en la noche centelleante, su nombre en los castillos hechos de pólvora que ardían en la Plaza Mayor vociferando: "iViva el Rey Fernando VII!".

Incluso en la representación escénica que se verificó en la noche del 23 de enero de 1809, cuando por boca de uno de los personajes se colma de vivas al legítimo rey de España e Indias: "... Viva y reine en todo/el Horbe nuestro invicto/Rey Fernando”. En fin, el carácter propagandístico de los rituales regios se manifestaba en cada instante de la fiesta, desde el pronunciamiento del pregonero que anunciaba los actos de la jura con el acompañamiento de cajas de guerra, trompetas y chirimías, hasta las manifestaciones lúdicas que tenían lugar en las calles, y especialmente, en la Plaza Mayor. La condición efímera de la fiesta era capaz de dejar un recuerdo indeleble en la memoria de los participantes-espectadores, puesto que el aparato escénico y gestual materializaba ideas y tópicos ya conocidos, un referente previo que se entreveraba con las percepciones físicas que se dirigín a estimular los cinco sentidos a través del ruido, el fuego, el olor, el colorido, las bebidas y comidas, las monedas...

Pero, hay más. El universo festivo fue diseñado de tal forma por el señor gobernador y las autoridades reales que permitiera no tan sólo legitimar la autoridad monárquica, sino el poder político local. Era uno de los momentos en que el grupo dominante y los sectores subalternos entraban en contacto y compartían un espacio común de ocio y alegría, por encima de sus divisiones, desigualdades y diferencias. También podía revelar la discontinuidad social que separaba a los unos de los otros en la sociedad colonial hispanoamericana. 


\section{—._Bibliografía}

\section{Fuentes primarias}

Archivo

Archivo Nacional de Costa Rica, Sección Histórica (ANCR)

Complementario Colonial (CC) 991, 1102, 1968 (1808) y 919, 993, 994, 2050 y 533 (1809).

Municipal Cartago (MC) 336.

Fuentes impresas

Archivo Nacional de Costa Rica. "Actas del Cabildo de Cartago 1800-1810". Revista de los Archivos Nacionales 43.1-6 (enero-junio de 1959): 7-174.

“Teatro Colonial”. Revista de Historia 34 (julio-diciembre de 1996): 179-221.

\section{Fuentes secundarias}

Acuña León, María de los Ángeles y Doriam Chavarría. "El mestizaje: la sociedad multirracial en la ciudad colonial de Cartago 1738-1821". Tesis de Licenciatura en Historia. Universidad de Costa Rica, 1991.

Alvarenga Venotulo, Patricia. "Resistencia campesina y formación del mercado de bienes básicos: Cartago, 1750-1820”. Revista de Historia 31 (enero-junio 1995): 41-67.

Avedaño Rojas, Xiomara. "Las características de la ciudadanía en Centroamérica durante el siglo XIX: estudio de los distritos electorales de Quetzaltenango y Granada”. Revista de Historia 5-6 (1995): 20-9.

Backzo, Bornislaw. Los imaginarios sociales: memorias y esperanzas colectivas. Buenos Aires: Nueva Visión, 2005.

Bajtin, Mijail. La cultura popular en la Edad Media y el Renacimiento: el contexto de François Rabelais. Madrid: Alianza, 1999.

Balandier, Georges. El poder en escenas: de la representación del poder al poder de la representación. Barcelona: Paidós, 1994.

Bauer, Arnold. Somos los que compramos. Historia de la cultura material en América Latina. México: Taurus, 2002.

Benavides Murillo, Clotilde. "Reflexiones sobre la formación y función social de los artesanos en Cartago en el siglo XVIII". Revista Estudios 18-19 (2004-2005): 25-38.

Brenes Zúñiga, Andrés. "Arquitectura urbana cartaginesa: siglo XX”. Tesis de Licenciatura en Arquitectura. Universidad de Costa Rica, 2003. 
Breña, Roberto. El primer liberalismo español y los procesos de emancipación de América, 1808-1824. Una revisión historiográfica del liberalismo hispánico. México: El Colegio de México, 2006.

Calderón Gómez, Juan Carlos. "Moros y cristianos en Cartago (Baile de Conquista)". Escena 13.27 (1991): 20-25.

Cañedo Gamboa, Sergio. Los festejos septembrinos en San Luis Potosí: protocolo, discurso y transformaciones, 1824-1847. México: El Colegio de San Luis, 2001.

Cañeque, Alejandro. "De sillas y almohadas o de la naturaleza ritual del poder en la Nueva España de los siglos XVI y XVII”. Revista de Indias 64.232 (2004): 609-34.

Cárdenas Gutiérrez, Salvador. "De las juras reales al juramento constitucional: tradición e innovación en el ceremonial novohispano, 1812-1820". La supervivencia del derecho español en Hispanoamérica durante la época independiente. México: Universidad Nacional Autónoma de México, 1998.19 marzo $2007<$ http:www. bibliojuridica.org/libros >.

Chacón Hidalgo, Manuel Benito. Monedas de Costa Rica: reseña histórica. San José, Costa Rica: Universidad de Costa Rica-Fundación Museos del Banco Central de Costa Rica, 2003.

Chartier, Roger. El mundo como representación. Historia cultural: entre práctica y representación. Barcelona: Gedisa, 1995.

Chavarría Jiménez, Sandra. Las estructuras de dominación en Costa Rica: de la época colonial a los albores del Estado Nacional. San José, Costa Rica: Universidad Estatal a Distancia, 1993.

Chiaramonti, Gabriella. Ciudadanía y representación en el Perú, 1808-1860: los itinerarios de la soberanía. Lima: Universidad Nacional Mayor de San Marcos, 2005.

Chust Calero, Manuel. "El rey para el pueblo, la constitución para la nación". El Imperio sublevado: monarquía y nacionesen España e Hispanoamérica. Eds. Víctor Mínguez y Manuel Chust. Madrid: Consejo Superior de Investigaciones Científicas, 2004.225-54.

Colom González, Francisco. "El trono vacío: la imaginación política y la crisis constitucional de la monarquía hispánica". Relatos de nación: la construcción de las identidades nacionales en el mundo hispánico. Vol. 1. Ed. Francisco Colom. Madrid: Iberoamericana-Vervuet, 2005.23-50.

Coto Monge, Rogelio. Las ruinas de la parroquia: un sueño roto. Cartago, Costa Rica: Editorial Cultural Cartaginesa, 1993.

Dachner Trujillo, Yolanda. "Centroamérica: una nación antigua en la modernidad republicana”. Anuario de Estudios Centroamericanos, 24.1-2 (1998): 7-20. 
Darnton, Robert. "Un burgués pone en orden su mundo: la ciudad como texto". La gran matanza de gatos y otros episodios en la historia de la cultura francesa. México: FCE, 2000. 109-47.

Díaz Arias, David Gustavo. "Invención de una tradición: la fiesta de la Independencia durante la construcción del Estado costarricense, 1821-1874". Revista de Historia 45 (enero- junio 2002): 105-162.

Dym, Jordana. "La soberanía de los pueblos: ciudad e independencia en Centroamérica, 1808-1823”. Revolución, independencia y las nuevas naciones de América. Coord. Jaime Rodríguez. Madrid: Mapfre-Tavera, 2005.309-37.

---. "Soberanía transitiva y adhesión condicional: lealtad e insurrección en el Reino de Guatemala, 1808-1811”. 1808: la eclosión juntera en el mundo hispano. Coord. Manuel Chust Calero. México: FCE-El Colegio de México, 2007. 105-37.

Estrada Molina, Ligia. "Don Tomás de Acosta: gobernador de Costa Rica”. Tesis de Licenciatura en Historia. Universidad de Costa Rica, 1962.

Fajardo de Rueda, Marta. "La jura del Rey Carlos IV en la Nueva Granada”. Anales del Instituto de Investigaciones Estéticas 74-75 (1999): 195-209.

Fernández Bonilla, León. Historia de Costa Rica durante la dominación española (1502-1821). San José, Costa Rica: Editorial Costa Rica, 1975.

Fernández Esquivel, Franco. Crónicas y tradiciones de Cartago. Cartago, Costa Rica: Uruk, 2008.

---. La Plaza Mayor: génesis de la nación costarricense. Cartago, Costa Rica: Editorial Cultural Cartaginesa-Uruk, 1996.

Fernández Guardia, Ricardo. Crónicas coloniales. San José, Costa Rica: Editorial Costa Rica, 1991.

Ferrer Valls, Teresa. "La fiesta en el Siglo de Oro: en los márgenes de la ilusión teatral". Teatro y fiesta del Siglo del Oro en tierras europeas de los Austrias. Madrid: Seacex, 2003.27-37.

Fonseca Corrales, Elizabeth y Enrique Barascout. "Historia de la arquitectura colonial". Historia de la arquitectura en Costa Rica. Eds. Elizabeth Corrales y José Enrique Garnier. San José, Costa Rica: Fundación de Museos del Banco Central de Costa Rica, 1998.81-149.

Frasquet Miguel, Ivana. "Alteza versus majestad: el poder de la legitimidad en el Estadonación mexicano, 1810-1824". El imperio sublevado: monarquía ynaciones en España e Hispanoamérica. Eds. Víctor Mínguez y Manuel Chust. Madrid: Consejo Superior de Investigaciones Científicas, 2004. 255-276. 
Gagini, Carlos. Diccionario de costarriqueñismos. 1918. San José, Costa Rica: Editorial Costa Rica, 2008.

Garavaglia, Juan Carlos. "Del Corpus a los toros: fiesta, ritual y sociedad en el Río de la Plata colonial”. Anuario del IEHS 16 (2001): 391-420.

Garrido Asperó, María José. Fiestas cívicas históricas en la Ciudad de México: 1765-1823. México: Instituto de Investigaciones Doctor José María Luis Mora, 2006.

Gayol, Víctor. "El retrato del Escondido. Notas sobre un retrato de jura de Fernando VII en Guadalajara”. Relaciones. Estudios de Historia y Sociedad 83 (verano de 2000): 151-81.

Gil Calvo, Enrique. El estado de fiesta: feria, foro, corte y circo. Madrid: Espasa-Calpe, 1991.

Ginzburg, Carlo. "Representación: la palabra, la idea, la cosa”. Ojazos de madera: nueve reflexiones sobre la distancia,. Barcelona: Ediciones Península, 2000. 85-103.

Gonzalbo Azpuru, Pilar. "Las fiestas novohispanas: espectáculo y ejemplo”. Mexican Studies 9.1 (1993): 19-45.

González Pérez, Marcos. "La idea de nación". Urdimbres y tramas en la investigación interdisciplinaria. Comps. José Eduardo Rueda y Marcos González. Bogotá: Cooperativa Editorial Magisterio, 1998.47-81.

Gruzinski, Serge. La guerra de las imágenes. De Cristóbal Colón a Blade Runner. 1492-2019. México: FCE, 1990.

Guerra, Fraçois-Xavier. Modernidad e independencias: ensayos sobre las revoluciones hispánicas. México: FCE, 2000.

Guerra, Fraçois-Xavier et al.Los espacios públicos en Iberoamérica: ambigüedades y problemas. Siglos XVIII-XIX. México: FCE, 1998.

Guevara Salazar, Eva María. "Fiestas profanas en la sociedad colonial". Vida cotidiana en la Colonia: 1680-1821. Seminario de Graduación de Licenciatura en Historia. Universidad de Costa Rica, 1994. 48-183.

Herrerón Peredo, Carlos. Del sermón al discurso cívico. México, 1760-1834. México: El Colegio de México-El Colegio de Michoacán, 2003.

Ibarra Rojas, Eugenia. Las manchas del jaguar: huellas indígenas en la historia de Costa Rica (Valle Central, siglos XVI-XX). San José, Costa Rica: Universidad de Costa Rica, 1999.

Jiménez Oreamuno, Manuel de Jesús. “Fiestas reales”. Noticias de Antaño. San José, Costa Rica: Imprenta Nacional, 1946. 53-68.

Kantorowicz, Ernst. Los dos cuerpos del rey. Madrid: Alianza, 1985.

Landavazo, Marco Antonio. La máscara de Fernando VII: discurso e imaginario monárquicos en una época de crisis. Nueva España. 1808-1822. México: El Colegio de México-Universidad Michoacana de San Nicolás de Hidalgo-El Colegio de Michoacán, 2001. 
Landavazo Marco Antonio. "La sacralización del rey: Fernando VII, la insurgencia novohispana y el derecho divino de los reyes”. Revista de Indias 61.221 (2001): 67-90.

Lepetit, Bernard. "Comunidad ciudadana, territorio urbano y prácticas sociales". Historiografía francesa: corrientes temáticas y metodológicas recientes. Pref. Hira de Gortari y Guillermo Zermeño. México: Instituto de Investigaciones Doctor José María Luis Mora, 1997. 125-44.

Lynch, John. América Latina: entre colonia y nación. Barcelona: Crítica, 2001.

Madrigal Muñoz, Eduardo. "La élite colonial de cara a las instituciones coloniales, 16001708”. Boletin AFEHC 20 (mayo 2006). 9 enero 2007. <http:www.afehc-historiacentroamerica.org $>$.

Martínez Villa, Juana. "La fiesta regia en Valladolid de Michoacán: política, sociedad y cultura en el México borbónico". Tesis de Maestría en Historia. Instituto de Investigaciones Históricas, Universidad Michoacana de San Nicolás de Hidalgo, 2006.

Meléndez Chaverri, Carlos. "Las Villas Nuevas en la Costa Rica Borbónica”. Costa Rica Colonial. Luis Fernando Sibaja (selección). San José, Costa Rica: Ediciones Guayacán, 1989. 165-77.

Mínguez Cornelles, Víctor. "Efímero mestizo". Iberoamérica mestiza: encuentro de pueblos y culturas. Dir. Víctor Mínguez. Madrid: Seacex-Fundación Santillana, 2003.49-65.

---."Fernando VII: un reyimaginado para una nación inventada”. Revolución, independencia y las nuevas naciones de América. Coord. Jaime Rodríguez. Madrid: MapfreTavera, 2005. 193-213.

Molina Jiménez, Iván. "Imagen de lo imaginario. Introducción a la historia de las mentalidades colectivas". Historia: teoría y métodos. Comp. Elizabeth Fonseca. San José, Costa Rica: Editorial Universitaria Centroamericana, 1989. 179-224.

---. Costa Rica (1800-1850). El legado colonial y la génesis del capitalismo. San José, Costa Rica: Universidad de Costa Rica, 1991.

Molina Montes de Oca, Carlos. Y las mulas no durmieron... Los arrieros en Costa Rica. Siglos XVI al XIX. San José, Costa Rica: Universidad Estatal a Distancia, 2005.

Moya Gutiérrez, Arnaldo. "La vida cotidiana en la Provincia de Costa Rica: 1750-1820". Costa Rica: desde las sociedades autóctonas hasta 1914. Coord. Ana María Botey. San José, Costa Rica: Universidad de Costa Rica, 2002, 173-207.

Obregón Loría, Rafael. De nuestra historia patria: las autoridades coloniales superiores de Costa Rica. San José, Costa Rica: Universidad de Costa Rica, 1979.

Osorio, Alejandra. El Rey en Lima: el simulacro real y el ejercicio del poder en la Lima del diecisiete. Documento de trabajo No. 140. Lima: Instituto de Estudios Peruanos, 2004. 
Page, Carlos. "Las proclamaciones reales en Córdoba del Tucumán". Revista Complutense de Historia de América 30 (2004): 77-94.

Pérez Brignoli, Héctor. Breve historia contemporánea de Costa Rica. México: FCE, 1997.

Quesada Camacho, Juan Rafael. Educación y ciudadanía en Costa Rica de 1810 a 1821: del crepúsculo colonial al umbral de la modernidad. San José, Costa Rica: Universidad de Costa Rica, 2007.

---."Elideario dela Revolución Francesa en Cádiz: aproximación al estudio dela construcción de la nación costarricense”. Revista del Archivo Nacional 69.1-12 (2005): 105-55.

Rojas Nieto, Beatriz. Documentos para el estudio de la cultura politica de la transición: juras, poderes e instrucciones. Nueva España y la Capitanía General de Guatemala. 1808-1820. México: Instituto de Investigaciones Doctor José María Luis Mora, 2005.

Ross González, Marjorie. Entre el comal y la olla: fundamentos de gastronomía costarricense. San José, Costa Rica: Universidad Estatal a Distancia, 2001.

Ruiz Medrano, Carlos Rubén. Fiestas y procesiones en el mundo colonial novohispano: los conflictos de preeminencia y una sátira carnavalesca del siglo XVIII. México: El Colegio de San Luis, 2002.

Saénz Carbonell, Jorge Francisco. “¡Viva nuestro Rey Fernando! (Albores del teatro costarricense)". Revista Nacional de Cultura 27 (1995): 55-81.

Solórzano Fonseca, Juan Carlos. "La sociedad colonial 1575-1821". Costa Rica: desde las sociedades autóctonas hasta 1914. Coord. Ana Botey Sobrado. San José, Costa Rica: Universidad de Costa Rica, 2002. 115-72.

Solórzano Fonseca, Juan Carlos y Claudia Quirós Vargas. Costa Rica en el siglo XVI: descubrimiento, exploración y conquista. San José, Costa Rica: Universidad de Costa Rica, 2006.

Valenzuela Márquez, Jaime. "De las liturgias del poder al poder de las liturgias: para una antropología política de Chile colonial". Historia 32 (1999): 575- 615.

Zárate Toscazo, Verónica. "Del regocijo a la penitencia o del carnaval a la cuaresma en la Ciudad de México en el siglo XIX”. Gozos y sufrimientos en la historia de México. Coord. Pilar Gonzalbo Aizpiru y Verónica Zárate Toscazo. México: El Colegio de México-Instituto de Investigaciones Doctor José María Luis Mora, 2007. 203-34.

Fecha de recepción: 19 de enero de 2009.

Fecha de aprobación: 16 de marzo de 2009. 